\title{
38. COMMISSION POUR L'ECHANGE DES ASTRONOMES
}

Président: Prof. M. G. J. Minnaert, Sterrewacht 'Sonnenborgh', Zonnenburg 2, Utrecht, The Netherlands.

Vice-Président: Prof. P. Swings, Directeur de l'Institut d'Astrophysique de l'Université de Liège, Cointe-Sclessin, Belgium.

Comité D'Organisation: B. J. Bok, A. A. Mikhailov, T. L. Page.

Membres: Abetti, Bappu, Bowen, Danjon, Keller, Kienle, Kourganoff, Miyamoto, Mohr, Pawsey†, Righini, Rosseland, Sahade, Stoy, Thackeray, Witkowski, Wood (F. B.), Woolley, Wyatt.

Since the last report in 1960 , a total number of 25 grants has been made to 27 astronomers. This is about the average number of the last ten years. Considering the increasing importance of astronomy, one might have expected a quicker development of international travel and exchange. All efforts should be made to stimulate the mobility of astronomers and to make effective use of the wonderful possibilities now available. It should be stressed that the IAU grants can be awarded for a stay of any duration of time, and that practically all applications are answered positively and quickly.

In the last three years, the following awards have been made:

roo. An Australian astronomer to England, France and Göttingen.

I0I. A Czechoslovak astronomer to Victoria.

102. A Polish astronomer to the Netherlands.

I03. An Italian astronomer to Liège.

104. A Hungarian astronomer to Asiago.

105. A British astronomer to Meudon.

ro6. A British astronomer to Jungfraujoch.

107. A Belgian astronomer to Tenerife.

108. A Spanish astronomer to Haute-Provence.

109. A British astronomer to Canberra.

I I0. An Indian astronomer to East-Cleveland.

III. Two French astronomers to Capetown.

I12. A French astronomer to Herstmonceux.

I13. A Yugoslavian astronomer to Manchester.

114. A Polish astronomer to Tucson.

II5. A Japanese astronomer to Heidelberg.

II6. A Greek astronomer to Manchester.

I17. A Japanese astronomer to Sydney.

I18. A Dutch astronomer to Ondřejov.

I19. Two Czechoslovak astronomers to Utrecht.

120. An Italian astronomer to Austin.

121. A French astronomer to London.

122. A Czechoslovak astronomer to Nagoya.

I23. A Czechoslovak astronomer to Utrecht.

124. A Greek astronomer to Arcetri.

The work undertaken at foreign observatories by these astronomers may be classified under the following headings: 
(a) observations with photo-electric photometers, spectrographs, radio-astronomical instruments;

(b) study of instruments, instrument construction, special techniques, mostly in view of future developments at the home observatory;

(c) study of plate collections and records;

(d) theoretical discussion;

(e) training of able young astronomers in order to build up a staff for newly-developing countries.

In a special case astronomers were exchanged in order to assist in the site-selection for a new observatory. In two cases, the visit has led to a scientific collaboration between the home and the host observatory (special variable stars; atmospherics).

Three grants concerned travels towards or from the southern hemisphere; two related to radio-astronomy. In the field of space research, no applications were received, probably because there are other resources for such purposes. Of the 25 grants, Io concerned East-West relations, a considerably higher proportion than ever before reached. It remains surprising, that no applications were received for travels from one to another of the Eastern countries.

Exchanges among astronomers of the southern hemisphere should be particularly encouraged, in view of their relative isolation.

One of the subsidies was granted to an astronomer, wishing to make use at another observatory of his sabbatical year. This example might encourage others, who are in a similar position.

During the three years $1961-1963$ the grants totalled $\$ 13402$. The balance at hand on 3 I December $196_{3}$ is $\$ 8006 \cdot 47$. The annual allocations from the Union amounted to $\$ 7500 \times 3=$ $\$ 22500$.

By an announcement in Information Bulletin no. 8, applicants were requested to apply by preference in the months of January and July, in order to facilitate the planning of the expenditure. There is no indication that this request has had any effect, but up to now no real administrative difficulties have been met.

Conforming to the wishes expressed at the Berkeley meeting, the following letters were written by the President. (I) To the National Academy of Sciences, Washington, asking that the time-lag between the application for a Fulbright award and the starting time of the fellowship should be shortened; the Executive Secretary replied that all attention is being given to our request and that improvement has already been reached. (2) To the Ministry of Education of some countries, asking that NATO fellowships should be made available also for visits of short duration; notice was received that in future short-term awards for periods between two and four months will be granted.

\section{New Activities of the Commission}

In October 1962 the Executive Committee requested our Commission to extend its activities to questions concerning the training of astronomers in foreign countries. The President prepared a memorandum, in which the remarks of several members of the Commission were included, which was presented by him at the special session of the Executive Committee in Liège in July I963. A recently revised version of this memorandum is appended to this report.

At this meeting, the much more general question was raised whether the IAU should institute a Commission on the teaching of astronomy, both nationally and internationally. It was decided to explore the practicability of holding a larger meeting of those interested during the twelfth General Assembly at Hamburg in 1964. The President of Commission 38 agreed to arrange such a meeting, emphasizing, however, that our Commission as such should keep to its original 
programme. The General Secretary promised to assist by publishing a preparatory questionnaire.

At the request of the Executive Committee, the President attended as an observer the meeting of the Inter-Union Committee on Science Teaching in Rome, in August 1963. It seems important that astronomy be represented on this Committee, in which ten other sciences collaborate.

It was suggested that the Commission should publish a booklet on the study of astronomy, intended for prospective students and for student advisers. Examples: $A$ Career in Astronomy (Amer. Astr. Soc., I962); Blätter zur Berufskunde, IC4; Astronom (Bielefeld, Bertelsmann Verlag, r957). The great differences between the regulations in the individual countries would have to be taken into account.

M. G. J. MinNaERT

President of the Commission

APPENDIX I. FACILITIES FOR VISITING ASTRONOMERS

In general the directors of observatories are very willing to receive visiting astronomers and to offer them observational facilities, but often there is no scholarship or fellowship attached to the observatory. The following list includes only those institutes where some assistance for visitors may be available locally. For all observatories not in the list below the procedure for a young astronomer would be to apply directly to the Director of the Observatory, indicating the nature of the research that he wishes to carry out.

For general information on facilities for study or research in other countries, the book Study Abroad, published by UNESCO, will be found very helpful.

\section{Australia}

Canberra. The Mount Stromlo Observatory is the Department of Astronomy of the Australian National University in Canberra. The University offers two scholarships for post-graduate study in Astronomy with preference for students from overseas. The annual scholarship award is of the order of $£^{85}$ (Australian) and the scholarships are generally tenable for a period of three years. All inquiries should be addressed to the Director of Mount Stromlo Observatory, Canberra, A.C.T.

Sydney. The Division of Physics of the Commonwealth Scientific and Industrial Research Organization is prepared to consider applications for fellowships for theoretical or observational research in solar physics: structure of the photosphere and chromosphere; studies of disturbances involving these layers (sunspots, flares, prominences, plages); the development of new types of observational equipment. The fellowships may be at junior or senior level in the approximate range of $£_{1500}$ or $£ 3500$ (Australian) annually. All inquiries should be addressed to The Chief, Division of Physics, C.S.I.R.O., University Grounds, Sydney, New South Wales.

The Division of Radiophysics offers from time to time fellowships for work in radio astronomy. The conditions for remuneration are the same as for solar physics. All inquiries should be addressed to The Chief, Division of Radiophysics, C.S.I.R.O., University Grounds, Sydney, New South Wales.

\section{Belgium}

Liège. Occasional temporary assistantships. Apply to the Director, Institut d'Astrophysique, Cointe-Sclessin. 
American astronomers may get help under the Belgian-American Educational Foundation Inc., Graybar Building, 420 Lexington Avenue, New York.

\section{Canada}

Post-doctorate fellowships, National Research Council. Fellowships of $\$ 4000$ a year for single fellows and $\$ 5000$ a year for male fellows who are married. Tenure: one year, but renewable. Travel grant allowed. Applicants must be not more than 35 years of age and should possess a Ph.D. degree (or equivalent) from a recognized University. Apply to the Awards Office, National Research Council of Canada, Ottawa or to the Chief Scientific Liaison Officer, National Research Council of Canada, Africa House, Kingsway, London, W.C.2, England. These fellowships are tenable at:

Kingston, Ontario, Queen's University.

London, Ontario, University of Western Ontario.

Ottawa, Dominion Observatory. Fellowships tenable for geomagnetism, gravity, positional astronomy, stellar physics and seismology.

Pentincton, British Columbia, Dominion Radio Astrophysical Observatory for researches in radio astronomy.

Toronto, Astronomy Department of the University and David Dunlap Observatory. The University of Toronto also has post-graduate fellowships available tenable at the David Dunlap Observatory.

Victoria, British Columbia, Dominion Astrophysical Observatory. Fellowships tenable for stellar atmospheres, galactic structure, photo-electric photometry, spectroscopic binaries, interstellar matter.

\section{Eire}

Dunsink. One Scholarship every two years at the Dublin Institute for Advanced Studies in the School of Cosmic Physics. Qualification: an honours degree in mathematics, physics or astronomy, with evidence of capacity for original research. Apply to the Registrar, Dublin Institute for Advanced Studies, 9-10 Burlington Road, Dublin.

\section{Germany}

For fellowships tenable at astronomical observatories and institutions apply, after securing the approval of the chosen institution, to: the Deutsche Forschungsgemeinschaft, Frankengraben 40, Godesberg, or to the Deutscher Akademischer Austauschdienst, Bad Godesberg, Frankengraben $5 \circ$.

Tautenberg. Applications should be sent to the Director.

\section{India}

Kodaikanal. For young Indian students with a M.Sc. or equivalent degree. Four Research Scholarships of Rs. 2400 a year. Apply to the Director, Astrophysical Observatory, Kodaikanal.

Naini Tal. Two Fellowships for one year, with a possibility of renewal, for photometric work. Apply to the Director, U.P. State Observatory, Naini Tal.

\section{Italy}

After securing the approval of the Director of the observatory where the student wishes to work, apply for a fellowship to the: Presidente della Commissione Nazionale per l'astronomia, Consiglio Nazionale delle Ricerche, Piazzale delle Scienze 7, Rome. 


\section{Netherlands}

Leiden. Occasional vacancy for a young astronomer on the staff for a period between six months and a year.

Utrecht. Occasional exchanges of astronomers for a period of three to six months.

In each observatory there may be a room available free of charge in the observatory. Apply in each case to the Director.

South Africa

Radcliffe Observatory, Pretoria. See Oxford.

\section{Switzerland}

Zürich. Foreign astronomers may be able to obtain an assistantship to work in solar research for a period ranging between several semesters and several years. Apply to the Director, Swiss Federal Observatory, Zürich.

\section{United Arab Republic (Egyptian region)}

Helwan. Assistantship for two years. Visiting professorship for limited time.

\section{United Kingdom}

Cambridge. The Isaac Newton Studentship of $£ 500$ a year, with the possibility of an additional grant not exceeding $£ 5^{\circ}$ a year for approved expenses. This Studentship is open to graduates of any University, under 25 years of age on I January of the year of election. Apply to the Registrar, University Registry, Cambridge, by 25 March each year with evidence of age, evidence of qualifications, testimonials and a statement of proposed course of study or research.

Oxford. Radcliffe Travelling Fellowship to be held partly at Oxford University Observatory and partly at the Radcliffe Observatory, Pretoria. Vacancies are advertised from time to time as they occur. Apply to the Director, Oxford University Observatory.

Skynner Senior Studentship for students working for a research degree. Apply to the Master, Balliol College, Oxford.

Scotland. Robert Cormack Fellowships in Astronomy, $£ 300$ to $£ 600$ a year for three years. Tenable at the Universities of Edinburgh, Glasgow or St Andrews in the case of graduates outside Scotland. Apply to the Convener, Robert Cormack Bequest Committee, Royal Society of Edinburgh, 22 George Street, Edinburgh 2.

$$
\text { U.S.A. }
$$

Austin-McDonald. Graduate student fellowships and assistantships to outstanding foreign students, with stipends from $\$ 1800$ to $\$ 2400$ a year. Post-doctorate fellowships, with the duration from I September to 3 I August, normal stipend $\$ 7000$. Apply to the Director, McDonald Observatory, Astronomy Department, The University of Texas, Austin, Texas.

Berkeley. One Lick Fellowship of $\$ 2000$ a year for a graduate student, usually for theoretical astrophysics. Apply to the head of the Berkeley Astronomical Department, Leuschner Observatory, Berkeley 4, California.

Boulder. Joint Institute for Laboratory Astrophysics. Fellowships for graduate study in Astronomy, covering the fields of laboratory physics, atomic physics, aerodynamics, applied to astrophysics. Inquiries should be directed, depending on the interest of the student, to the Chairman of the Departments of Physics and Astrophysics, Aerospace Engineering Sciences, or Astrophysics and Atmospheric Physics. In addition, about ten stipends a year are granted for 
visiting members; round-trip transportation costs between home and Boulder will be covered over and above the stipend. Apply to the Secretary for Visiting Members, JILA, I 5 I I University Avenue, Boulder, Colorado.

California Institute of Technology. Graduate fellowships for study for the doctor's degree. Apply to the Dean of Graduate Studies, California Institute of Technology, Pasadena, California.

Dyer Observatory. One assistantship for qualified graduate students. Apply to the Director, Dyer Observatory, Nashville, Tennessee.

Flower and Cook. Assistantships and fellowships; Pawling fellowship (\$1800 a year). Apply to the Director of the Flower and Cook Observatory, University of Pennsylvania, Philadelphia 4, Pennsylvania.

Harvard. Agassiz and other fellowships and assistantships. Apply to the Director, Harvard College Observatory, Cambridge, Massachusetts.

Kirkwood. Assistantships and fellowships. Apply to the Director, Kirkwood Observatory, Indiana.

Leander McCormick. Fellowships of one year in the fields of astrometry, instrumentation, radio-astronomy. Apply to the Director, Leander McCormick Observatory, University of Virginia, Charlottesville, Virginia.

Lick. Two Lick Observatory Fellowships of $\$ 2000$ a year. Apply to the Director, Lick Observatory, Mount Hamilton, California.

Los Angeles. University of California. Assistantships for graduate work in astronomy. Apply to the chairman of the Department of Astronomy, University of California, Los Angeles 24, California.

Michigan. Assistantships for graduate students; post-doctoral fellowships in astronomy. Apply to the Department of Astronomy, The University of Michigan, Ann Arbor, Michigan.

Mount Wilson and Palomar. Carnegie Fellowships for men who have recently received doctor's degree. Apply to the Director, Mount Wilson and Palomar Observatories, 813 Santa Barbara Street, Pasadena 4, California.

Perkins. Fellowships of the Ohio State University. Apply to the Director, Perkins Observatory, Delaware, Ohio.

Rochester. Assistantships for graduate work in astronomy, astrophysics, cosmic ray physics. Occasional funds for visiting astronomers. Apply to the Chairman, Department of Physics and Astronomy, University of Rochester, Rochester, New York.

Van Vleck. Fellowships and assistantships in the field of positional astronomy and astrophysics. Apply to the Director, Van Vleck Observatory, Wesleyan University, Middletown, Connecticut.

Warner and Swasey. Part-time assistantships for graduate students; occasional post-doctoral fellowships. Apply to the Director, Warner and Swasey Observatory, East Cleveland, Ohio, 44II2.

Yerkes. Post-graduate research fellowships and assistantships. Apply to The Director, Yerkes Observatory, Williams Bay, Wisconsin.

American Astronomical Society. Each year the Society awards eight Foreign Visiting Professorships to distinguished astronomers from overseas. No one can apply for these positions; candidates are nominated by the university or observatory where they will serve for a period of about four months and are paid salary and travel expenses from funds provided by the National 
Science Foundation. Further information is available from Prof. Dr Paul Routly, The Executive Officer, AAS, 21 I FitzRandolph Road, Princeton, New Jersey.

\section{U.S.S.R.}

The largest astronomical institutions of the Academy of Sciences and the Ministry of Higher Education have facilities for visiting astronomers from other countries in an exchange programme. The Academy and the Ministry decide on any application, which has to be made through diplomatic channels.

It would be appreciated if directors of observatories in the above list would send corrections or additional details to the President of Commission 38.

Directors of observatories not included in the above list who have fellowships or occasional assistantships available for visiting astronomers are also asked to send details.

\section{APPENDIX II. TRAINING OF YOUNG ASTRONOMERS IN FOREIGN COUNTRIES}

The training of young astronomers is a very general problem, which will be considered here only from the point of view of the co-operation between different countries and exchanges.

In countries with a high scientific level, training abroad will primarily be useful for students who have already reached the M.A. degree. It is an invaluable experience to work for some time at an institute where the very best work in a special field is being done and where first-hand acquaintance with the methods and instruments may be obtained.

For the 'new' countries, the training abroad of younger students at a lower level will also play a great role. Such a training should not be directed towards permanent emigration but towards a return to the home country. It will not be sufficient to find institutes, where foreign students of new countries are welcome, and to grant the necessary support and financial aid. It will be just as necessary to encourage such countries to send some of their best students abroad, and to have them guarantee more or less that these shall get suitable positions when they return, so that the knowledge which they have acquired may be put to good use. One could require the student to sign a written guarantee that he will not reside in the host country for some stated period following the visit.

I. The teaching of undergraduate students should take place in the home country. If assistance is necessary, UNESCO might help by sending experts, as is already done with success for the teaching of mathematics in co-operation with the International Mathematical Union. Most interesting is a regulation, established in Belgium since $196 \mathrm{I}$, by which a scientist, finishing the University training as a teacher (engineer, doctor, etc.), is exempt from military service if he agrees to stay for at least three years in one of the developing countries.

2. For the teaching of graduate students, up to the level corresponding to the M.A. degree, the existing facilities at home should primarily be used.

(a) For new countries, where no training in astronomy at this level is available, it would be useful to send the students to centres where astronomy, mathematics, physics have reached a high level. Before accepting such students, a personal recommendation from their university should be requested, since the level of foreign diplomas is often considerably less than that of the corresponding European or American diplomas. All efforts must be made to explain, to the educational authorities in such countries, that today a good knowledge of physics is even more necessary than that of mathematics as a preparation for astronomical studies.

It has been suggested to bring not one student, but a small group, from the new country to the host country. In such a case the students will be able to help each other, and they will feel 
less isolated; on the other hand they will less quickly master the language and adapt themselves to the customs of the host country.

There is always the danger that the young foreign scientists, after completion of their studies in Europe or the U.S.A., go back to their country and are able to find only very subordinate positions, where they lose all contact with science. Their knowledge will only bear fruit if it has some connection with their future scientific environment; otherwise they cannot stand the isolation and will try to go back to the host country.

(b) For countries with a normal scientific level, training abroad should be more or less exceptional and restricted to some of the ablest students.

It might be worth while to have some UNESCO international fellowships in astronomy, for which students from all over the world can compete. One or two written papers on certain specified topics and a research project might be the requirements for such a fellowship, which could be awarded by a panel of Commission 38 . Such a procedure would help to discover the most able young people available in any country.

It may be questioned whether training in the biggest countries and at the most celebrated institutes is always to be preferred. In smaller countries, and at not too populated universities, students may find more personal contact and guidance. In countries where the scientific level of the individual universities is very different (U.S.A.), they should receive good advice about the universities which are best adapted to their knowledge.

A rather good knowledge of the language in the host country is essential, for the students must be able to follow normal courses and exercises. In many big countries the students and part of the staff do not speak foreign languages fluently; a foreign guest, not knowing the language of the country, would feel very isolated. This would be especially detrimental in countries where the teaching is mainly done by lectures. It would thus be useful to organize, for foreigners, preparatory language courses of $3-6$ months, as it is done with great success in Germany (a few central courses for the whole country), at Leiden and elsewhere.

It seems desirable that the study of astronomy should lead to examinations and to a diploma. Many countries will object to the granting of a normal M.A. diploma to students who have not passed through the complete training at each level, that is required from their own nationals. In such cases it might be possible to arrange a special diploma for foreigners, which would have no legal value in the host country but would be important for the home country.

Another possibility would be to organize courses on astronomy for graduate foreign students at one or a few central institutes in some of the big countries (U.S.A., U.S.S.R.). In Holland there is at Eindhoven a Philips International Institute, where normally about 30 foreign students are being trained. At such institutes it would be desirable, for obvious reasons, to have also a number of 'autochthonous' students. However, education at an ordinary university has the advantage that the foreigner becomes entirely familiar with the scientific 'climate', and with the mentality of the students, and that any artificial set-up is avoided.

Financial provisions for such a study of 2-3 years should be made. Already now there are a number of grants available (See Appendix I and UNESCO annual publication: Study Abroad). It would seem reasonable that both the home country and the host country contribute. Able students might earn part of their money by serving as assistants. This question is probably one of the most important and difficult, to which full attention should be given. It might be necessary to make a selection between the applicants.

3. Perhaps the most important question concerns the training of students who have already reached a level corresponding to the $M$. A. degree. It would be especially valuable for them to get experience in working with astronomical instruments or in specialized theoretical research.

(a) The use of plate-measuring machines and micro-photometers is especially important for 
countries not having at their disposal telescopes of a sufficient size. This can be learned almost everywhere, already during the training for the M.A. degree.

(b) Very important is training in telescopic work. Strong advice should be given not to insist on working with the very best or largest instruments, unless proper experience has been acquired with medium telescopes. For students coming from countries with limited instrumental means, training on problems that require a large instrument has little value; on returning home they will often become discouraged and give up research. On the other hand if they had learned to do useful work with medium instruments they might carry this on in their own country. Modest instruments of little scientific use, say with an objective of $30 \mathrm{~cm}$, may be converted into excellent training telescopes, by equipping them with a photo-electric photometer, a micrometer, a spectrograph, a photographic arrangement. For those wishing to work with radiotelescopes, some knowledge of electronics is essential.

(c) Only the ablest among the foreign young astronomers will get the possibility of working with some of the really big instruments. They may assist one of the senior scientists, learn to devise a programme, serve as night-assistants, take part in the critical study of the plates obtained. Later they may become more independent.

(d) Training in centres of high scientific level is not only important in order to learn observational techniques. In order to become familiar with a specialized field of theoretical research, it is immensely helpful to work together with a group, at a centre where such subjects are being investigated by several workers.

(e) Observers, as well as theorists, should learn how to use electronic computation and digitization, punched cards, etc. Training abroad may help to introduce modern computers into countries where such machines are not yet available.

It should be emphasized that routine work with a telescope, or the measuring of plates, has only a limited value unless the student has also a good theoretical background.

The financial questions are of the same kind and of the same importance as for section 2. They may be solved more easily, since the guest students by their work are contributing in a useful way to the scientific activity of the host institute.

An entirely different solution may be found, if the 'new' country has some valuable instruments but lacks competent astronomers and technical assistance to exploit them. In such cases it would be of great value if a good scientist would be willing to work for some years abroad and to train students in the country itself. This might be an excellent task for retired astronomers! Perhaps more easy to realize would be the visit of a qualified astronomer to one of the 'new' countries for a period varying between one and six months. A systematic course, some stimulating lectures, and informal talks with staff and students could be very helpful.

The problem of technical assistance will be almost equally difficult to solve and not less important. It is related to the general technical level of the country. This seems to be a field where UNESCO might assist. It would seem more practical to send technicians temporarily to train men locally, than to send young technical students abroad for training, since in the latter case it might be more difficult to guarantee their permanent retention in the astronomical field.

\section{Practical steps}

Up to now Commission $3^{8}$ has taken care almost exclusively of the exchange and travels of professional astronomers or of young astronomers above the M.A. level. It would seem useful and possible to extend these activities and to take care also of the exchange of students at the graduate level. It might be necessary to constitute a special Committee for this purpose, which would be a central point to which all requests should be addressed. It should have in several 
countries an adviser, to whom the foreign students could be directed. From him they could get information about the possibilities available.

In the U.S.A. the co-ordination might be arranged by the Executive Officer of the American Astronomical Society, Dr Paul Routly (Princeton). Dr Routly could take care of an efficient distribution over different universities of the $20-30$ foreign students, who could be admitted in the country.

UNESCO has already several times shown interest in this field of education and close contacts with this organization should be maintained. (a) UNESCO could primarily encourage the training of undergraduate students (section $\mathrm{I}$ ). It would be very useful if UNESCO could administer a standard examination in mathematics, physics, astronomy to students having completed the undergraduate training. (b) For training at higher levels (sections 2 and 3 ) a regular financial contribution by UNESCO to Commission 38 would seem entirely justified. This Commission is especially qualified to make a selection, if necessary; to distribute the young astronomers among the different observatories; and to estimate the importance of the programmes which they intend to pursue. $(c)$ UNESCO might also facilitate the granting of visas for scientists, in such cases where difficulties occur. (d) UNESCO could help by sending technicians to new countries, in order to train local technical personnel.

Commission $3^{8}$ has already several times published a circular on observing facilities for foreign students. This list should be kept up to date.

\section{G. J. MinNaERT}

\section{NOTE}

The teaching of astronomy, physics, mathematics, is very different from one country to another. Just to fix ideas we shall try to define somewhat better what we have called the levels of 'Graduate Students' and of 'M.A.'

B.A. degree = Graduate Students. These are assumed to have learned: trigonometry and calculus, the simplest differential equations, theory of probability; mechanics (without Hamilton), thermodynamics, kinetic theory, physical optics, electromagnetism, elementary atomic theory; spherical astronomy (the essentials of Smart); astrophysics, up to the level of Struve, Siedentopf, Schatzman.

$M . A$. degree. These students are assumed to have learned: ordinary and partial differential equations; some advanced theoretical physics (Hamiltonian mechanics, statistical mechanics, quantum mechanics, relativistic electromagnetism); electronics; the essentials of Unsöld, Ambartsumian, or Aller.

This is by no means a complete enumeration of what a modern astronomer should have studied! On the other hand no harm is done if some points of this programme are lacking; they may be replaced by others of comparable importance. 